\title{
Individual-based model of larval transport to coral reefs in turbulent, wave-driven flow: behavioral responses to dissolved settlement inducer
}

\author{
M. A. R. Koehl ${ }^{1, *}$, J. A. Strother ${ }^{1,4}$, M. A. Reidenbach ${ }^{2}$, J. R. Koseff ${ }^{2}$, M. G. Hadfield ${ }^{3}$ \\ ${ }^{1}$ Department of Integrative Biology, University of California, 3060 Valley Life Sciences Building, Berkeley, California 94720-3140, USA \\ ${ }^{2}$ Environmental Fluid Mechanics Laboratory, Department of Civil and Environmental Engineering, Stanford University, Palo Alto, \\ California 94305-4020, USA \\ ${ }^{3}$ Kewalo Marine Laboratory, University of Hawaii, 41 Ahui Street, Honolulu, Hawaii 96813, USA
}

${ }^{4}$ Present address: Department of Ecology and Evolution, 321 Steinhaus Hall, University of California, Irvine, California 92697-2525, USA

\begin{abstract}
Larvae of many benthic marine animals settle and metamorphose in response to waterborne chemical cues. Can the behavioral responses of microscopic larvae in the water column to dissolved chemical cues affect their transport to the substratum in the turbulent, wave-driven flow characteristic of many shallow coastal habitats? We addressed this question using an individual-based model of larvae of the sea slug Phestilla sibogae, transported in the oscillatory flow above coral reefs. Larvae of $P$. sibogae stop swimming and sink in response to a dissolved inducer released by their prey, the coral Porites compressa, and resume swimming when exposed to inducer-free water. The instantaneous fine-scale spatial distribution of inducer in the flow above a reef is filamentous; hence microscopic larvae swimming or sinking through the water encounter inducer above threshold concentration in on/off temporal patterns. Model results show that using a time-averaged inducer concentration gradient to calculate larval transport rates to the reef overestimates the rates by $<15 \%$ (depending on the threshold concentration of inducer required to trigger larval sinking) compared with those calculated using time-varying, fine-scale inducer distributions. Aspects of larval behavior that have large effects on rates of transport to the substratum are swimming speed and direction, sinking speed, and sensitivity (threshold concentration) and responsivity (percent of encounters eliciting a response) to inducer. In contrast, lag times to start sinking after encountering inducer or to resume swimming after re-entering inducer-free water, have negligible effect.
\end{abstract}

KEY WORDS: Larvae - Settlement $\cdot$ Benthic $\cdot$ Waves · Turbulence $\cdot$ Phestilla $\cdot$ Chemical cue $\cdot$ Settlement inducer

Resale or republication not permitted without written consent of the publisher

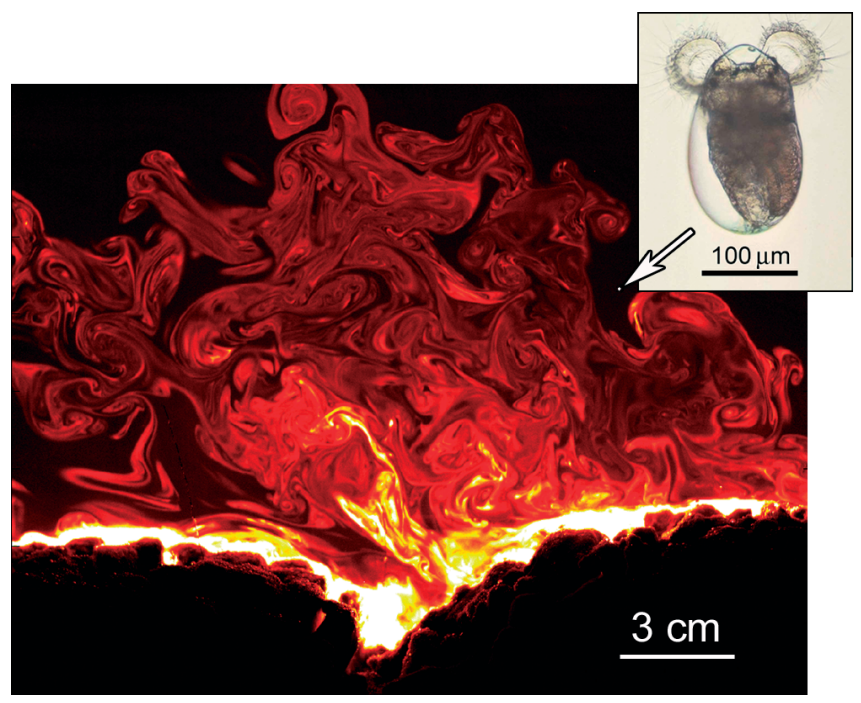

An odor cloud from a coral reef exposed to waves is made up of filaments, as illustrated by this laser-illuminated slice through a cloud of dye. Microscopic larvae of the coral-eating sea slug Phestilla sibogae (inset) sink when encountering filaments of odor from their prey, and resume swimming in odorfree water. This on/off response enhances their transport into the reef.

Photos: Matthew Reidenbach \& Jeffrey Koseff (laser image), Michael Hadfield (inset)

\section{INTRODUCTION}

Many bottom-dwelling marine animals produce planktonic larvae whose dispersal and recruitment to benthic sites can affect the dynamics and genetics of local populations and regional metapopulations, as well as the structure of benthic communities (reviewed 
in e.g. Roughgarden et al. 1987, Eckman 1996). The first step in larval recruitment is the transport of larvae from the water column to the substratum.

\section{Transport of larvae to the substratum in turbulent flow}

The roles played by physical processes and active larval behavior in determining where larvae settle on the substratum have been reviewed by Butman (1987), Eckman et al. (1994), and Abelson \& Denny (1997). Water flow in the benthic boundary layer (the region of fluid in which a velocity gradient exists between the substratum and the freestream flow) is turbulent; hence, eddies mix dissolved substances, larvae, and other particles between the freestream flow and the substratum. Although initial contact of larvae with benthic surfaces is often due to such physical processes in the benthic boundary layer (e.g. Hannan 1984, Havenhand \& Svane 1991, Harvey et al. 1995), the locations in which larvae settle can be affected by their behavior after contact (e.g. Grassle \& Butman 1989, Mullineaux \& Butman 1991, Pawlik 1993, Walters et al. 1997). In this study, we examine whether the behavior of larvae before contact with the substratum can affect their transport across the benthic boundary layer to the bottom in a wave-driven flow.

Most studies of larval settlement in moving water have been conducted in laboratory flumes in unidirectional currents, even though many shallow coastal habitats are subjected to wave action. Water motion near the substratum at shallow sites is oscillatory and can be characterized by high instantaneous velocities, accelerations, and turbulence, but by slow net horizontal transport across the habitat (e.g. Koehl 1977, Denny 1988, Koehl \& Powell 1994, Koehl \& Hadfield 2004).

The effect of water motion on larval settlement has been explored in several theoretical studies. Most models have treated larvae as passive sinking particles carried across the habitat by moving water (advection) and spread by turbulent mixing (diffusion). Such advection-diffusion models for both unidirectional (Eckman 1990) and wave-driven (Gross et al. 1992) flow have shown that turbulence increases the transport of larvae to the bottom by as much as an order of magnitude. Similarly, an advection-diffusion model of the surf zone of a rocky shore showed that turbulence dominates the transport of larvae to the substratum (Denny \& Shibata 1989). McNair used a local exchange model to calculate the time for larvae to encounter the substratum (McNair et al. 1997, McNair 2000). All these models treated larvae as negatively buoyant passive particles that may or may not reject the substratum upon contact. In contrast, Eckman et al. (1994) developed a 1-dimensional model of the flux of larvae settling through a turbulent bound- ary layer in which the response of larvae to a dissolved chemical cue from the substratum was treated as a steep increase in the downward velocity of the larvae as they neared the bottom. This downward motion in response to a chemical cue in the water significantly enhanced settlement rate.

\section{Dissolved chemical cues can affect larval behavior}

Larvae of many species of benthic marine animals are induced to settle and undergo metamorphosis by dissolved chemical cues released from organisms such as conspecifics or prey on the substratum (reviewed by Hadfield \& Paul 2001). Most research on larval responses to chemical cues has focused on the induction of metamorphosis and has been conducted in still water in the laboratory. However, a few studies investigated the short-term effects of dissolved chemical cues on the swimming behavior of larvae in the water column (e.g. Boudreau et al. 1993, Welch et al. 1997, Hadfield \& Koehl 2004). In addition, several studies of oyster larvae in unidirectional flow in a laboratory flume showed that they respond to dissolved inducer in the water and that behavioral changes of larvae in the water column can affect their motion towards the substratum (Turner et al. 1994, Tamburri et al. 1996, Finelli \& Wethey 2003).

Although past analyses of larval settlement assumed a smooth concentration gradient of dissolved chemical cues from the benthos (e.g. Crisp 1974, Eckman et al. 1994), recent flume studies revealed the instantaneous fine-scale distribution in the benthic boundary layer of dissolved substances released from the substratum. Video imaging of fluorescent dye released from the substratum and illuminated by a thin sheet of laser light (planar laser-induced fluorescence, PLIF) has shown that chemical cues from flat surfaces (e.g. Crimaldi \& Koseff 2001, Koehl et al. 2001, Mead et al. 2003), coral reefs (Reidenbach 2004), and other complex surfaces (Koehl 2006) are dispersed in the water above the substratum as fine filaments of high concentration swirling in clean water (see Fig. 3A). Such filaments tend to be wider and higher in concentration, and to be mixed farther from the substratum into the water column in wave-driven flow than in unidirectional currents (Mead et al. 2003, Reidenbach 2004, Koehl 2006). On the scale of a microscopic larva, such a patchy, rapidly changing cue distribution would be experienced as a series of on/off encounters as the larva swims or sinks into and out of cue filaments, rather than as the continuous gradient assumed in the past. In the present study, we use a numerical model to explore the consequences of rapid behavioral responses by larvae to brief on/off encounters with dissolved settlement inducer to their transport to the substratum. 


\section{Phestilla sibogae larvae and Porites compressa reefs}

We developed our model of larval transport to the substratum based on the behavior of larvae of the nudibranch Phestilla sibogae. Competent larvae (i.e. larvae that are developmentally capable of metamorphosis) of $P$. sibogae settle and metamorphose in response to a water-borne chemical cue released by their post-metamorphic prey, Porites compressa (e.g. Hadfield 1977, Hadfield \& Pennington 1990), an abundant coral that forms reefs in shallow habitats in Hawaii where they are exposed to wave-driven flow (Koehl \& Hadfield 2004). Dissolved inducer from $P$. compressa accumulates in the slow-moving water within the reefs in concentrations high enough to induce larvae to sink (Hadfield \& Koehl 2004), undergo metamorphosis (Hadfield \& Scheuer 1985, Hadfield \& Koehl 2004), and adhere to surfaces (Koehl \& Hadfield 2004). PLIF measurements of the instantaneous finescale filamentous structure of cue distributions in the water above a $P$. compressa reef have been made in a wave-flume (Reidenbach 2004) in which the smallscale turbulence and time-varying velocity profiles measured in the field (Koehl \& Hadfield 2004, M. A. R. Koehl \& T. Cooper unpubl. data) were mimicked.

The behavior of larvae of Phestilla sibogae exposed to brief on/off encounters with filaments of inducer from Porites compressa has been measured, as have their trajectories when they were moving freely in aquaria filled with clean seawater or seawater containing inducer from P. compressa (Hadfield \& Koehl 2004). Competent larvae swim along relatively straight paths in many different directions at instantaneous velocities of $\sim 0.17 \mathrm{~cm} \mathrm{~s}^{-1}$ until they encounter filaments of water containing inducer from $P$. compressa. In inducer filaments, a competent larva typically stops beating its cilia, retracts its velar lobes (swimming organs), and sinks at velocities of $\sim 0.13 \mathrm{~cm} \mathrm{~s}^{-1}$ with its foot extended (Fig. 1). This response usually starts about $1 \mathrm{~s}$ after the inducer first contacts the apical sensory organ, where the receptors for cue from $P$. compressa are located (Hadfield et al. 2000). After exiting a filament of inducer, competent larvae re-extend their velar lobes and resume swimming. The responsivity of the larvae to inducer depends on its concentration. The threshold concentration of inducer required to cause the sinking response is between 3 and $17 \%$ of the concentration of inducer in the water between the heads of $P$. compressa in the field (Hadfield \& Koehl 2004). As inducer concentration is increased above threshold, larvae respond to a greater percentage of the filaments encountered; at concentrations just above threshold, competent larvae respond to $\sim 27 \%$ of the inducer filaments they encounter, whereas at concentrations found within heads of $P$. compressa in the field, larvae respond to $\sim 80 \%$ of the cue filaments encountered.

\section{Objectives}

The goal of our study was to explore whether the instantaneous responses of larvae to encounters with dissolved settlement inducer released from the substratum can affect larval transport to the substratum while they are being carried in turbulent, wave-driven water flow. We used an individual-based numerical model of larvae of Phestilla sibogae in wave-driven flow above a Porites compressa reef to address this issue. The model enabled us to study not only the behaviors and flow conditions that have been measured for these species, but also allowed us to vary specific behavioral and flow parameters to determine their effects on larval transport across the boundary layer to the reef. We addressed the following questions:

(1) Are the rates of transport of larvae to the substratum calculated using a time-averaged inducer concentration gradient (as used in previous models of larval transport) different from those calculated using the actual fine-scale, time-varying inducer concentrations?

(2) How does turbulence intensity affect larval transport to the reef, and does it overwhelm the effects of larval behavioral responses to inducer?

(3) Which, if any, aspects of larval behavior affect rates of transport of larvae to the substratum?

\section{MATERIALS AND METHODS}

We studied larval transport across the boundary layer to the substratum using a numerical model of wave-driven water flow above a coral reef. Our temporally varying flow fields were based on measurements
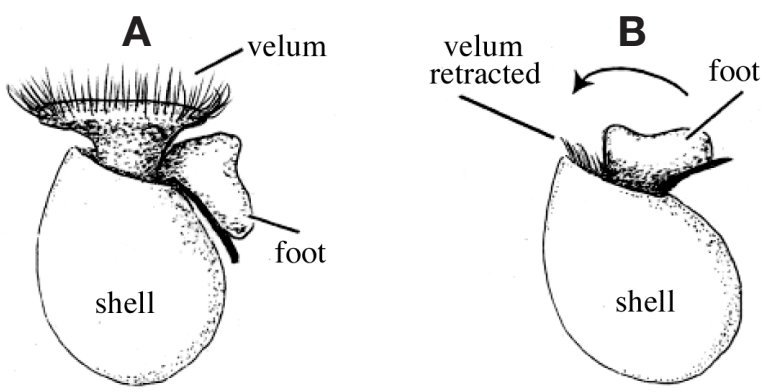

Fig. 1. Phestilla sibogae. Lateral view of a veliger larva. (A) The larva swims by beating cilia on the 2 lobes of its velum (only one lobe is visible from this lateral view). (B) When a larva encounters a dissolved settlement cue from the coral Porites compressa, it stops beating its cilia, retracts the velar lobes into its shell, and sinks with its foot protruding out of the shell (Hadfield \& Koehl 2004) 
of water velocities above a Porites compressa reef in a wave-flume, and our fine-scale temporally varying maps of inducer concentrations in the water were taken from PLIF videos of dye leaching from the coral surfaces in the flume under the same flow conditions. We used an individual-based model of instantaneous responses of larvae to the inducer concentrations they encountered as they were carried in the water flowing above the reef. The behavioral algorithms explored were based on those measured for competent larvae of the sea slug Phestilla sibogae.

Because the goal of this study was to determine whether larval responses to dissolved inducers before contact with the substratum could affect the rate that larvae are carried to the bottom by turbulent, wavedriven flow, we use the term 'transport' rather than 'settlement' (attachment of a larva to the substratum) or 'recruitment' (metamorphosis of a settled larva into the benthic form and survival) (e.g. Keough \& Downes 1982). Since concentrations of inducer high enough to affect larval behavior only occur in the water within 10 to $20 \mathrm{~cm}$ above a reef (Hadfield \& Koehl 2004, Reidenbach 2004), our model focused on the transport of larvae in that portion of the water column above a reef. Therefore, we did not examine larger-scale aspects of larval transport that are unaffected by dissolved inducer, such as transport by ocean currents to the vicinity of a reef, or vertical transport into the region of the water column on which we have focused. The latter was a reasonable approximation for reefs we studied in Kaneohe Bay, where height of the water surface above reefs was often only tens of centimeters.

When a larva arrived at or below the top surface of the reef, it was counted as 'transported to the reef' . A competent larva of Phestilla sibogae exposed to settlement inducer from the coral Porites compressa can adhere to a surface with its foot upon contact, but requires 1.5 to $2 \mathrm{~h}$ to develop a firm attachment (Koehl \& Hadfield 2004). Metamorphosis, which takes 12 to $24 \mathrm{~h}$, requires larval exposure to inducer of at least $6 \mathrm{~h}$ (Hadfield 1977). However, once larvae of $P$. sibogae enter the slow-moving water within the structure of a coral reef, they are likely to remain in contact with $P$. compressa inducer and surfaces for many hours, such that settlement and recruitment can occur (Koehl \& Hadfield 2004). Therefore, once a larva in our model arrived at the reef surface, we removed it from the water column. We defined the 'reef surface' by a horizontal line at the height of the tops of the branches of the convex coral heads in the PLIF videos (e.g. Fig. 3A). Test runs of the model using a line traced along the complex surfaces of the corals and the 'reef surface' yielded the same patterns of predicted larval transport rates as did runs of the model using the simple horizontal line, so we used the latter approximation to simplify the calculations.
Equations of motion. We defined a 2-dimensional coordinate system with the origin located at the surface of the coral. Positive $z$ displacements are toward the water's surface and positive $x$ displacements are in the direction of wave propagation. We assumed that larval behavior consists of choosing a velocity relative to the ambient flow:

$$
\frac{\mathrm{d} \vec{r}}{\mathrm{~d} t}=\vec{v}_{\mathrm{b}}+\vec{v}_{\mathrm{f}}
$$

where $\vec{r}$ is the position of the larva, $t$ is time, $\vec{v}_{\mathrm{b}}$ is the velocity of the larva relative to flow, and $\vec{v}_{f}$ is the ambient fluid velocity.

Flow field. Since we were interested in the effect on larval behavior of dissolved inducers released by the coral, and since those inducers are concentrated immediately above the reef (Reidenbach 2004), in this study we focused on the small-scale flow that occurs in the $20 \mathrm{~cm}$ immediately above the reef. We modeled the flow field as the linear summation of net flow, monochromatic waves, and turbulence:

$$
\vec{v}_{\mathrm{f}}=\vec{f}_{\mathrm{m}}(\vec{r})+\vec{f}_{\mathrm{w}}(\vec{r}, t)+\vec{f}_{\mathrm{t}}(\vec{r}, t)
$$

where $\vec{f}_{\mathrm{m}}(\vec{r})$ is the net flow, $\vec{f}_{\mathrm{w}}(\vec{r}, t)$ is the instantaneous wave velocity, and $\vec{f}_{\mathrm{t}}(\vec{r}, t)$ is the instantaneous turbulent velocity at time $t$. We modeled the net flow using a standard turbulent boundary layer profile (Denny 1988):

$$
\begin{aligned}
f_{\mathrm{m}, x} & = \begin{cases}\frac{u_{*}}{\kappa} \log \left(\frac{z-\alpha}{\beta}\right) & z \leq h_{1} \\
u_{\infty} & z>h_{1}\end{cases} \\
f_{\mathrm{m}, z} & =w
\end{aligned}
$$

where $h_{1}$ is the boundary layer thickness, $u_{*}$ is the shear velocity, $\kappa$ is von Karman's constant, $\alpha$ is the zero plane displacement, $\beta$ is the roughness height, $u_{\infty}$ is the free stream velocity, and $w$ is the net vertical velocity of the mean flow. Although the boundary layer of an oscillatory flow is thinner than that of a steady current, a log profile can be used for the boundary layer of a current with superimposed waves (Grant \& Madsen 1979), as we used in the flume. In this case, fluid velocities were measured in the wave-flume under the same flow conditions for which the PLIF videos were taken (as described below), and then fit to the above model of the boundary layer profile.

We modeled the wave component of the velocity as monochromatic waves:

$$
\begin{aligned}
& f_{\mathrm{w}, X}=A_{X} \cos (2 \pi \omega t+\phi) \\
& f_{\mathrm{w}, z}=A_{z} \sin (2 \pi \omega t+\phi)
\end{aligned}
$$

where $\omega$ is the wave frequency, $\phi$ is a phase constant, $A_{x}$ is the maximum horizontal wave velocity, and $A_{z}$ is the maximum vertical velocity of the orbital water motion in the waves. We will refer to $A_{x}$ and $A_{z}$ as 'maximum wave orbital velocity' in the horizontal or 
vertical directions, respectively. The flow parameters used in our model of the boundary layer, and the functions we used for $A_{x}$ and $A_{z}$ (which vary with height above the reef), were based on measurements made over a Porites compressa reef in a wave-flume (Reidenbach 2004), as described below.

In these wave-flume experiments (Reidenbach 2004), turbulent velocities above the reef varied in a sinusoidal manner, with peak turbulence occurring during flow reversal. Thus, we assumed that the velocity fluctuations due to turbulence varied sinusoidally and were taken from a normal distribution:

$$
\begin{aligned}
& f_{\mathrm{t}, x}=\sqrt{2} \sin ^{2}(2 \pi \omega t+\phi) g\left(\sigma_{x}\right) \\
& f_{\mathrm{t}, z}=\sqrt{2} \sin ^{2}(2 \pi \omega t+\phi) g\left(\sigma_{z}\right)
\end{aligned}
$$

where $g(\sigma)$ is a Gaussian random variate with mean zero and variance $\sigma^{2} ; \sigma_{x}{ }^{2}$ is the variance of the horizontal velocity, and $\sigma_{z}{ }^{2}$ is the variance of the vertical velocity (approach reviewed in Gousbet \& Berlemont 1999). An example of a Gaussian fit to our ADV (Acoustic Doppler Velocimeter) data is given in Fig. 2C. We used velocity measurements in the wave-flume to determine how $\sigma_{X \prime} \sigma_{z \prime}$ and $\sigma_{x z}$ varied with height above the coral (Fig. 2D,E). While this statistical model of turbulence does not completely describe the full frequency spectrum and spatial coherence of actual turbulence, it serves as a close approximation of the flume data.

Flow parameters. Values for the flow parameters mentioned above were chosen to reflect measured velocities. ADVs (Sontek $16 \mathrm{MHz}$ micro-ADV) (M. A. R. Koehl \& T. Cooper unpubl. data) and electromagnetic flow probes (Marsh-McBirney 511 and 523) (Koehl \& Hadfield 2004) were used to measure the fluid velocity profiles and turbulence intensity and spectra above Porites compressa reefs in Kaneohe Bay,

Fig. 2. Flow velocities measured above a convex coral head on a Porites compressa reef in Kaneohe Bay, Hawaii, and velocities measured above a $P$. compressa reef constructed in a flume. (A) Mean peak horizontal velocities of each wave in

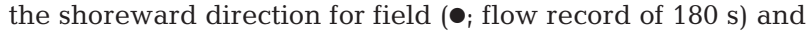
flume $(\mathrm{O}$; flow record of $60 \mathrm{~s})$ velocity measurements made at various heights above the coral reef surface. Error bars: $1 \mathrm{SD}$. (B) Power spectral density of the vertical velocity fluctuations $5 \mathrm{~cm}$ above the reef in the flume (O) and in the field (•). Error lines for field data: $95 \%$ confidence intervals. Flume data fall within the field measurement range except at the lowest frequencies, which could not be mimicked due to practical limits on the wavelengths that could be created in the flume. (C) Distribution of turbulent vertical velocities $10.1 \mathrm{~cm}$ above reef in flume compared with Gaussian distribution used in our model for turbulent vertical velocities at that height (black line). Measurements for (B,C) as described for (A). (D) Horizontal turbulence (points) at various heights above a $P$. compressa reef constructed in a flume (Reidenbach 2004) compared with modeled turbulence (line) used in our simulations (see 'Material and methods'). (E) Vertical turbulence (measured as in Fig. 2D) compared with modeled turbulence
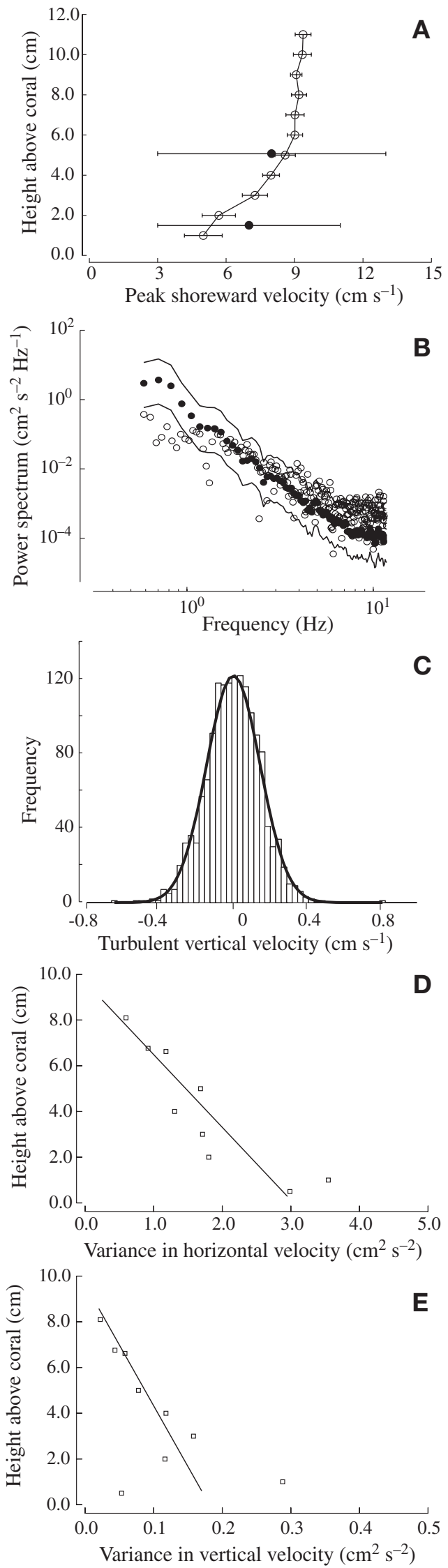
Hawaii (Fig. 2A,B). These field data were used to guide the design of flow in a wave-flume at the Environmental Fluid Mechanics Laboratory at Stanford University (Fig. 2A-E). A 'coral reef' was constructed from skeletons of $P$. compressa placed in the bottom of the flume, and detailed ADV (Sontek $10 \mathrm{MHz}$ ) measurements of the wave-driven flow above this reef were made. The flume ADV data were used to calculate the flow parameters used in our model.

The wave-flume is described in detail in Reidenbach et al. (2006). The working section of the flume was $9 \times$ $0.6 \mathrm{~m}$. A continuous, mean flow of water was generated using a constant head tank (4 $\mathrm{m}$ tall) at the upstream end of the flume. Waves with periods of up to $5 \mathrm{~s}$ were generated using a plunger-type wavemaker driven up and down by a motor positioned above the downstream weir of the flume. When the wavemaker plunger (a horizontal PVC cylinder $10 \mathrm{~cm}$ in diameter) was moved down and submerged in the flume, it prevented water from leaving the test section, thus setting up a wave that propagated upstream. Waves reflected off the upstream end the flume and returned downstream. By oscillating the wavemaker at a harmonic of the flume resonance frequency, wave amplitudes built over a number of cycles to such an extent that wave crests spilled over the top of the wavemaker cylinder, at which point wave amplitudes became constant. The coral 'reef' in the flume was composed of Porites compressa skeletons collected in Kaneohe Bay, Hawaii, from water depths of $\sim 1 \mathrm{~m}$ (Koehl \& Hadfield 2004). The typical size of corals was $15 \mathrm{~cm}$ in diameter by $15 \mathrm{~cm}$ in height and the corals were positioned in the flume to recreate the 3-dimensional structure of the reef found in Hawaii. The total coral canopy covered a length of $3.0 \mathrm{~m}$ in the flume and spanned the entire width, and the boundary layer was fully developed in the section of the flume where our data were collected (1.8 $\mathrm{m}$ downstream from the leading edge of the reef). In total, approximately 80 individual corals were positioned within the flume. The water depth for all experiments was $40 \mathrm{~cm}$.

The boundary layer parameters were calculated by averaging the instantaneous horizontal velocity profile over 15 waves and fitting this profile with a non-linear curve-fitting routine (Mathworks, Matlab R12): $u_{*} / \kappa=$ $0.827 \mathrm{~cm} \mathrm{~s}^{-1} ; \alpha=-0.735 \mathrm{~cm} \beta=0.727 \mathrm{~cm}$. The free stream velocity, $u_{\infty}$, was calculated by averaging the horizontal flow velocity for 15 waves at positions above $10 \mathrm{~cm}$ and found to be $u_{\infty}=2.1 \mathrm{~cm} \mathrm{~s}^{-1}$. The boundary layer thickness, $h_{1}$, was taken as the height at which the logarithmic boundary layer profile intersects with $u_{\infty}$ and found to be $h_{1}=8.2 \mathrm{~cm}$. The wave frequency, $\omega$, was calculated by performing a Fourier transform on the instantaneous horizontal fluid velocities and calculating the location of the dominant peak, and found to be $\omega=0.34 \mathrm{~Hz}$.
In order to calculate the maximum wave orbital velocities $A_{x}$ and $A_{z}$ the instantaneous flow velocities were filtered with a 4 th-order Butterworth low-pass filter at a cut-off frequency of 4 times the wave frequency. The maximum wave orbital velocity at each height above the coral was then calculated as:

$$
A=\left[\frac{2}{N} \sum_{i=1}^{N} s_{i}^{2}\right]^{1 / 2}
$$

where $s_{i}$ is the $i$ th measurement of the respective component. The modeled variation in the vertical maximum wave orbital velocities differs from that expected from shallow water wave theory, which predicts that the horizontal wave orbital velocity should be approximately constant while the vertical maximum wave orbital velocity goes as $(1+z / h)$ where $h$ is the height of the water column (Dean \& Dalrymple 1991). However, we found that vertical maximum wave velocities measured in the flume were poorly described by a linear model (linear regression, $\mathrm{R}^{2}=0.06, \mathrm{p}=0.49$ ), presumably as a result of interaction with the complex coral topography, but were well matched with a second order fit (polynomial regression, $\mathrm{R}^{2}=0.86, \mathrm{p}=0.002$; analyses done using MATLAB regression routines, $\mathrm{n}=9$ heights above the reef, data for 15 waves). Therefore, the horizontal and vertical wave orbital velocities were taken as $A_{X}=4.52 \mathrm{~cm} \mathrm{~s}^{-1}$ and:

$$
A_{z}=\left\{\begin{array}{cc}
\left(0.521 \mathrm{~cm} \mathrm{~s}^{-1}\right)+\left(0.423 \mathrm{~s}^{-1}\right) z & \\
\quad+\left(-5.42 \times 10^{-2} \mathrm{~cm}^{-1} \mathrm{~s}^{-1}\right) z^{2} & z \leq h_{1} \\
0.475 \mathrm{~cm} \mathrm{~s}^{-1} & z>h_{1}
\end{array}\right.
$$

Although ADV measurements of the horizontal and vertical velocities were made at several heights above the coral, measurements were not taken along the length of the reef (the $x$-direction). By neglecting local variation of the flow velocity in the $x$-direction as waves move across the reef, our empirically fit description of the wave component of the flow results in apparent compression of the water. Fortunately, this artifact averages to zero over each wave cycle and results in no net accumulation of larvae. To estimate the magnitude of this source of error on our calculated transport rates, the model was run with the maximum vertical wave orbital velocity held constant across all heights above the reef. Under these conditions, both the horizontal and vertical maximum wave orbital velocities are constant in the $z$-direction and the modeled flow is incompressible. We ran the model using 10 different vertical wave orbital velocities that represented the range of velocities measured in the flume at different heights above the reef. We found that the calculated transport rate for the lowest velocity we used $\left(0.37 \mathrm{~cm} \mathrm{~s}^{-1}\right)$ differed by $<2 \%$ from the highest velocity we used $\left(0.48 \mathrm{~cm} \mathrm{~s}^{-1}\right)$. The transport rate calculated when we used the second order fit of the profile of 
vertical wave orbital velocity at different heights above the reef (described above) was only $3 \%$ lower than the transport rate calculated when we used the heightindependent profiles.

As in previous studies (e.g. Denny \& Shibata 1989, Eckman 1990, Gross et al. 1992, Eckman et al. 1994), we modeled the turbulent transport of larvae to the substratum as a diffusion process. We estimated the vertical $\left(w^{\prime}\right)$ and streamwise horizontal $\left(u^{\prime}\right)$ velocity fluctuations due to turbulence from our ADV measurements taken at 11 heights above the reef in the flume. The velocity fluctuations due to turbulence, which were greatest near the reef surface and decreased with height above the reef, varied with phase during the wave cycle (Eqs. 7 and 8). At each time step the difference between the filtered fluid velocity (described above) and the instantaneous fluid velocity recorded using ADV was taken to be the turbulent velocity ( $w^{\prime}$ or $\left.u^{\prime}\right)$. The variance in this turbulent velocity was calculated at each height for 15 waves, and the variance for the horizontal $\left(\sigma_{x}^{2}\right)$ and vertical $\left(\sigma_{z}^{2}\right)$ velocity were approximated by linear functions of height above the reef:

$$
\begin{aligned}
& \sigma_{x}{ }^{2}= \begin{cases}\left(3.0 \mathrm{~cm}^{2} \mathrm{~s}^{-2}\right)+\left(-3.1 \mathrm{~cm}^{1} \mathrm{~s}^{-2}\right) z & z \leq h_{1} \\
0.89 \mathrm{~cm}^{2} \mathrm{~s}^{-2} & z>h_{1}\end{cases} \\
& \sigma_{z}{ }^{2}= \begin{cases}\left(0.18 \mathrm{~cm}^{2} \mathrm{~s}^{-2}\right)+\left(-0.019 \mathrm{~cm}^{1} \mathrm{~s}^{-2}\right) z & z \leq h_{1} \\
0.025 \mathrm{~cm}^{2} \mathrm{~s}^{-2} & z>h_{1}\end{cases}
\end{aligned}
$$

These functions were used in conjunction with a Gaussian-distributed random number generator to calculate the turbulent velocities in the vertical ( $\left.w^{\prime}\right)$ and streamwise $\left(u^{\prime}\right)$ direction for each time step (Eqs. 7 and 8). In our model $W^{\prime}$ and $u^{\prime}$ varied independently, whereas in the oscillatory flow in the flume, the covariance between $W^{\prime}$ and $u^{\prime}$ was greatest near the reef surface $\left(0.75 \mathrm{~cm}^{2} \mathrm{~s}^{-2}\right)$ and decreased linearly to zero (indicating turbulence is nearly isotropic) at a height of $\sim 12 \mathrm{~cm}$ above the reef (Reidenbach 2004). We ran our model using these measured values for height-dependent covariance between $w^{\prime}$ and $u^{\prime}$ and found the calculated larval transport rate to be only $1 \%$ lower than that predicted using the simplifying assumption of zero covariance.

Inducer concentration field. Rather than model the dissolved inducer released from coral into the water column as a time-averaged concentration gradient, as is usually done in models of chemotactic behavior, we considered the instantaneous, small-scale distribution of inducer as encountered by individual microscopic larvae in the turbulent water above a reef. Because the complex spatially and temporally varying concentrations of chemicals released from the substratum into a turbulent boundary layer is difficult to characterize either analytically or numerically, the inducer field used in the model was taken directly from empirical measurements.
The inducer field was measured using PLIF (see 'Introduction') in the wave-flume under the flow conditions described above (Reidenbach 2004). Dissolved chemical inducers released by the coral were simulated by fluorescent dye (Rhodamine 6G) leaching from gelatin on the surfaces of the coral skeletons. A vertical plane in the water was illuminated by an argon laser and scanning mirror apparatus that swept out a sheet of light $0.3 \mathrm{~mm}$ thick. Images were captured on a 12-bit CCD camera with a resolution of $1024 \times 1024$ pixels, a framing rate of $10 \mathrm{~Hz}$, and shutter speed of $20 \mathrm{~ms}$ (a typical frame is shown in Fig. 3A). The field of view was approximately $21 \times 21 \mathrm{~cm}$. The brightness of each pixel in a video frame was used to calculate the dye concentration at that point in the water column at that instant (described in Crimaldi \& Koseff 2001). Because there were no apparent trends across the width of the inducer field images, we assumed that the inducer field leaching off the corals was similar along adjacent sections of the reef. Therefore, in our calculations larvae exiting from one edge of an image (e.g the downstream side) re-enter the next video frame on the opposite edge (e.g. the upstream side).

To calibrate dye concentrations measured in the flume to inducer concentrations over real coral reefs, we used Phestilla sibogae metamorphosis bioassays to measure inducer activity in water collected in the field between the branches of Porites compressa (Hadfield \& Scheuer 1985, Hadfield \& Koehl 2004). We called inducer concentration in the water between coral branches 'in reef' concentration. We determined the 'in reef' concentration of dye in the flume from the brightness in our PLIF videos of pixels in the water between coral branches. All concentrations of inducer (for which the dye was an analog) were normalized to this 'in reef' concentration. Our behavioral study of $P$. sibogae larvae showed that the threshold concentration of inducer required to cause the sinking response was between 3 and $17 \%$ of the 'in reef' concentration (Hadfield \& Koehl 2004). In the present study we used a conservative estimate (15\% of 'in reef' concentration) for the inducer threshold we assumed for real $P$. sibogae larvae.

We synchronized the phase of the oscillatory flow to the phase of the visualized inducer field by tracking frame-by-frame distinguishable points in dye field in the PLIF video (43 s, 15 waves). These points showed close agreement with each other, indicating that the advective and oscillatory flow were tightly coupled to the inducer field. We used these measurements to phasematch the flow field based on the ADV measurements of water velocities (described above) with the timevarying inducer field recorded in the PLIF videos.

Our ADV measurements of the velocity fields and our PLIF measurements of the concentration fields 

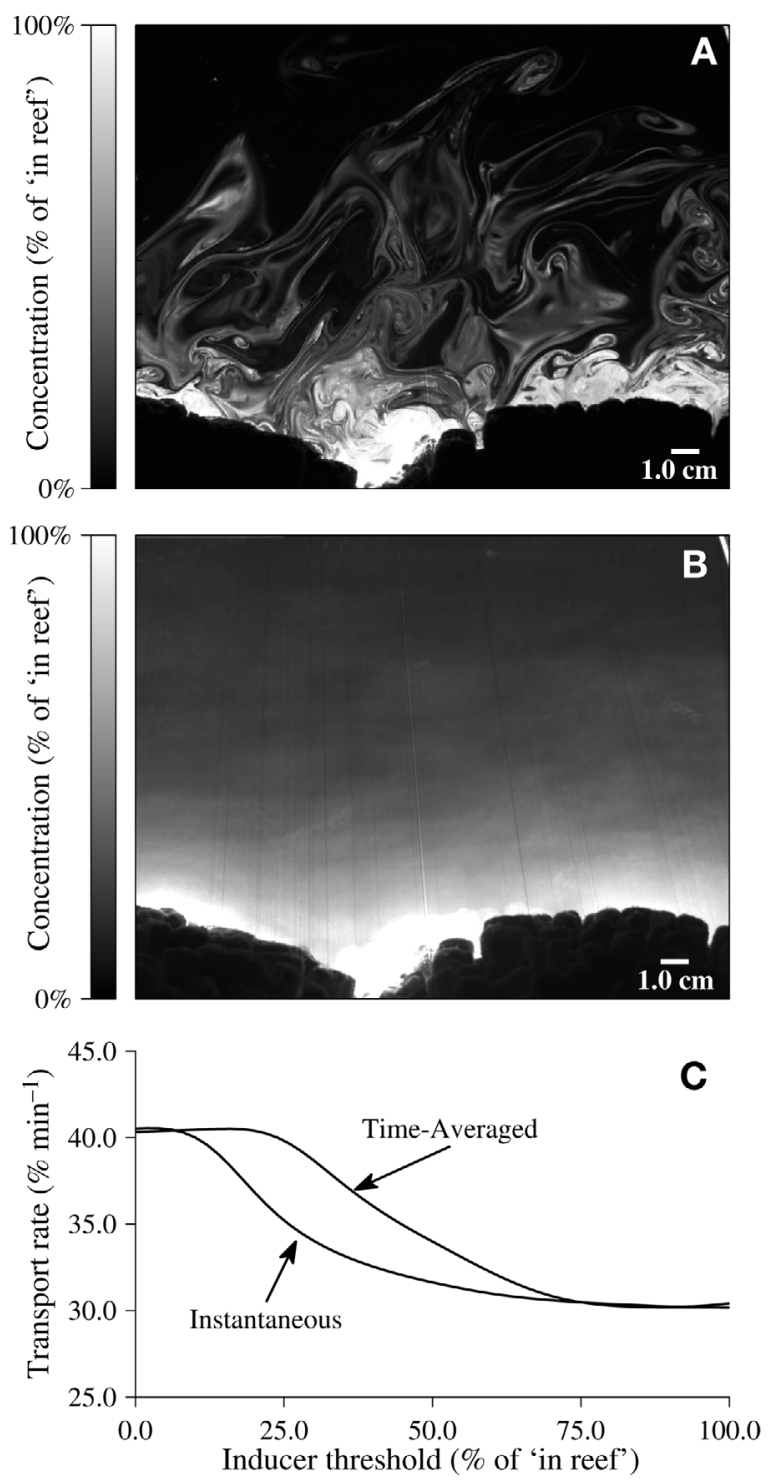

Fig. 3. Effect of a filamentous inducer field on the transport of larvae into the reef. (A) Frame from a PLIF video of fluorescent dye (inducer analogue), leaching into the water above the reef. (B) Time-averaged dye concentration in the water above the reef. (C) Rate at which larvae are transported into the reef as a function of inducer threshold (the concentration of inducer required to cause larval sinking). An inducer threshold of $100 \%$ indicates that the larvae never sink in response to cue and a threshold of $0 \%$ indicates that larvae sink continuously. Observed inducer threshold of competent Phestilla sibogae larvae is between 3 and $17 \%$ of the 'in reef' concentration (Hadfield \& Koehl 2004). Upper line in (C) calculated for larvae in the time-averaged field (B), and lower line calculated for larvae in the instantaneous time-varying field, e.g. (A). Other behavioral parameters as in Table 1 and flow conditions as measured in the flume (see 'Materials and methods')

were made under the same flow conditions in the flume, but they were not made simultaneously. Therefore, although changes in the height-dependent turbulence intensity that occurred during a wave cycle were phase-matched in our model to the images in the PLIF video, we did not have maps of velocity vectors in the water column measured at the instant that each PLIF image was captured. Consequently, we could not impose a correlation in our model between the turbulence field and the instantaneous inducer concentration field. Our statistical description of the spatial and temporal variation in the turbulence adequately modeled how larvae carried in the turbulent flow would be moved relative to the reef, but not relative to specific dye filaments. Therefore, in our model turbulence might carry larvae into or out of inducer filaments, whereas in reality larvae can only move relative to water around them (and thus can only move into and out of inducer filaments) by swimming or sinking. We attempted to circumvent this potential problem by using Scalar Imaging Velocimetry (SIV), which derives the velocity field from PLIF videos of the scalar field (Su \& Dahm 1996a,b). Unfortunately, this approach was not successful in our case because the velocity was poorly determined in the many dye-free gaps in the scalar field measured above our reef. Therefore, we employed several approaches to assess the consequences of using phase-matched turbulence and inducer fields that were not recorded simultaneously. As described in detail in the 'Discussion', the error resulting from this approximation appears to be small.

Larval behavior. The behavioral algorithm used by the larvae in our individual-based model was based on measurements of the responses of competent larvae of the sea slug Phestilla sibogae to encounters with different concentrations of dissolved inducer from the coral Porites compressa (Hadfield \& Koehl 2004), as described in the 'Introduction'. A model larva swam at a constant velocity $u_{\text {out }}$ in a randomly assigned direction (as do competent larvae of $P$. sibogae in inducerfree water in aquaria; Hadfield \& Koehl 2004). If the larva moved into an area with an inducer concentration greater than the threshold concentration, $\Gamma$, then the larva was said to be 'in an inducer filament.' Upon entering the inducer filament, a larva could either ignore the filament and keep swimming, or it could respond to the inducer and initiate sinking. A model larva made this decision by sampling from a random number generator and using the result to respond probabilistically to a percentage of inducer filaments; we called this percentage the 'larval responsivity,' $R$. If the larva did respond to the filament, then it began sinking with a constant velocity $u_{\text {in }}$ after an initial entrance lag time, $\tau_{\mathrm{in}}$. When a sinking larva exited the filament, it resumed swimming after an exit lag time, $\tau_{\text {out }}$. The swimming direction (angle in the $x, z$ plane) of the larva after exiting from the filament was set to the previous swimming direction plus a random, normally distributed perturbation that had a mean of zero and a 
variance of $\sigma_{\theta}^{2}$. We called this variance the 'reorientation variance.' Other than $\sigma_{\theta}^{2}$, we did not incorporate reorientation of larvae by turbulent eddies into our model because sinking larvae move downwards regardless of orientation, and because there are no data available for the reorientation variance for the larvae of $P$. sibogae in still water or in turbulent flowing water. Fortunately, the effect on larval transport rates of changing the magnitude of the reorientation variance was very small, as described in the 'Results'.

To explore the effects of various behavioral parameters on the rate at which larvae were transported to the reef, model runs were conducted in which a single parameter was independently varied while all other parameters were held fixed at the measured values for the competent larvae of Phestilla sibogae (Hadfield \& Koehl 2004) (Table 1). The responsivity varies between $27 \%$ for inducer concentrations just above threshold to $80 \%$ for 'in reef' concentrations of inducer (Hadfield \& Koehl 2004); we used a conservative estimate for responsivity of $27 \%$ in those simulations where responsivity was held constant.

Numerical simulations to calculate larval transport rates. We used the simple Euler method to calculate solutions for Eq. (1):

$$
\vec{r}(t+\delta t)=\vec{r}(t)+\frac{\mathrm{d} \vec{r}}{\mathrm{~d} t} \delta t
$$

We chose this method because Eq. (1) is a simple first-order differential equation that is unlikely to be sensitive to most numerical artifacts, and because it was necessary to calculate a very large number of solutions to determine the probability of larval transport into the reef. Higher order methods can yield more precise solutions to ordinary differential equations, but they require more computational power and would have substantially reduced the number of simulations we could have performed.

Table 1. Behavioral parameters describing the response of competent Phestilla sibogae larvae to dissolved chemical cues released by Porites compressa. All values taken from Hadfield \& Koehl (2004) with the exception of the reorientation variance which was found to be unimportant (see 'Results') and was chosen arbitrarily

\begin{tabular}{|lcc|}
\hline Variable & Symbol & Value \\
\hline Swimming speed & $u_{\text {out }}$ & $0.17 \mathrm{~cm} \mathrm{~s}^{-1}$ \\
Sinking speed & $u_{\text {in }}$ & $0.13 \mathrm{~cm} \mathrm{~s}^{-1}$ \\
Entrance lag & $\tau_{\text {in }}$ & $1.60 \mathrm{~s}$ \\
Exit lag & $\tau_{\text {out }}$ & $0.00 \mathrm{~s}$ \\
Inducer threshold & $\Gamma$ & $15 \%$ \\
Responsivity & $R$ & $27 \%$ \\
Reorientation variance & $\sigma_{\theta}^{2}$ & 0.100 \\
\hline
\end{tabular}

The time step we used in our calculations $(\delta t)$ was $0.1 \mathrm{~s}$, the interval between frames of our PLIF videos. To confirm that this $\delta t$ was sufficiently small to reduce error from our use of Euler's method and to satisfy the continuum approximation required by our stochastic model of turbulence, we ran several simulations with multiples of this time step. Even at $\delta t=0.2 \mathrm{~s}$, the transport rate increased by $<5 \%$ at the observed behavioral values and the effects of specific behavioral parameters on the transport rate were unchanged.

For our calculations of larval transport, we made several assumptions about the initial state of the population of larvae, treating them as though they had experienced no previous encounters with inducer. We assumed that (1) larvae were swimming isotropically at a speed of $u_{\text {out }}$ as they do in the absence of inducer (Hadfield \& Koehl 2004); (2) larvae were distributed randomly throughout the water column; and (3) the initial state of each larva was the same as if it had just exited an inducer filament to which it did not respond (i.e. both the time the larva had spent in an inducer filament and out of an inducer filament were set to zero). To refute the hypothesis that larval sinking in inducer enhances the rate of larval transport to the reef, these assumptions are conservative (i.e. they lead to lower transport rates than would be predicted if we assumed that some larvae were sinking in response to inducer at the start of the calculation).

We used a random-number generator to choose the coordinates in the water column at which 10000 larvae were placed at the start of each simulation. The trajectory for each larva was calculated as it was carried in the flow field described above and responded (using the behavioral algorithm described above) to the phase-matched inducer field it encountered. The calculation was performed for a trajectory that ran for $43 \mathrm{~s}$, or until the larva arrived at the reef surface. This period was sufficiently long that about $10 \%$ (depending on various behavioral and flow parameters) of the larvae were transported into the reef. We made the conservative assumption that larvae that were carried upwards through the top surface of the evaluation area were not transported back to the reef during the evaluation period (i.e. larvae that exited the top of the area were not replenished).

We calculated a 'steady-state' rate of transport that was not biased by the duration of the simulation. We assumed that the percentage of the population that settled per unit time was constant, and calculated the rate of transport as

$$
T=-\frac{1}{\Delta t} \log (1-S)
$$

where $T$ is the transport rate, $\Delta t$ is the duration of the simulation, and $S$ is the fraction of the population that 
have been transported to the substratum during the simulation. The transport rate as a function of time was recorded from a number of simulations and was found to be in very close agreement with this steady-state assumption.

Modeling turbulence as a simple stochastic process can introduce an artifact into calculations of the transport of particles if there is a spatial gradient in the turbulence (e.g. Hunter et al. 1993, Visser 1997, Yamazaki et al. 2002). In our case, this artifact could cause non-physical migration of larvae into areas of low variance. Using the correction term suggested by Hunter et al. (1993), we found that this bias was negligible (less than 1\%) compared to the larval sinking speed (Appendix 1); therefore, we have neglected it in our model for simplicity.

\section{RESULTS}

\section{Temporal variation in inducer concentration encountered by a larva}

A competent Phestilla sibogae larva is $\sim 230 \mu \mathrm{m}$ long, i.e. small relative to the filamentous structure of the field of dissolved inducer above a reef of Porites compressa (e.g. Fig. 3A). We calculated the temporal pattern of inducer concentrations encountered by individual larvae as they swam and sank through the time-varying inducer field. As the example in Fig. 4 illustrates, a $P$. sibogae larva encounters on-off pulses of inducer above threshold (i.e. the inducer concentration necessary to stimulate larval sinking) as it moves through the water flowing above a reef. The frequency and concentration of those pulses increase if the larva moves closer to the reef surface (compare Fig. 4A with Fig. 4B,C).

\section{Instantaneous vs. time-averaged inducer concentration}

Rates of transport of larvae to the reef in a timevarying filamentous inducer concentration field (Fig. 3A) were compared with rates in a smooth timeaveraged inducer field (Fig. 3B) constructed by averaging the instantaneous inducer concentration at each position over 12 waves. Larval transport rates in the time-averaged inducer field were greater than in the time-varying filamentous inducer field for a range of threshold concentrations (Fig. 3C). The greatest difference occurred at a threshold of $\sim 25 \%$ of the 'in reef' inducer concentration, where transport rate was overestimated by $15 \%$ when the constant, smooth concentration gradient was used in the calculations instead of the actual time-varying, filamentous inducer field.

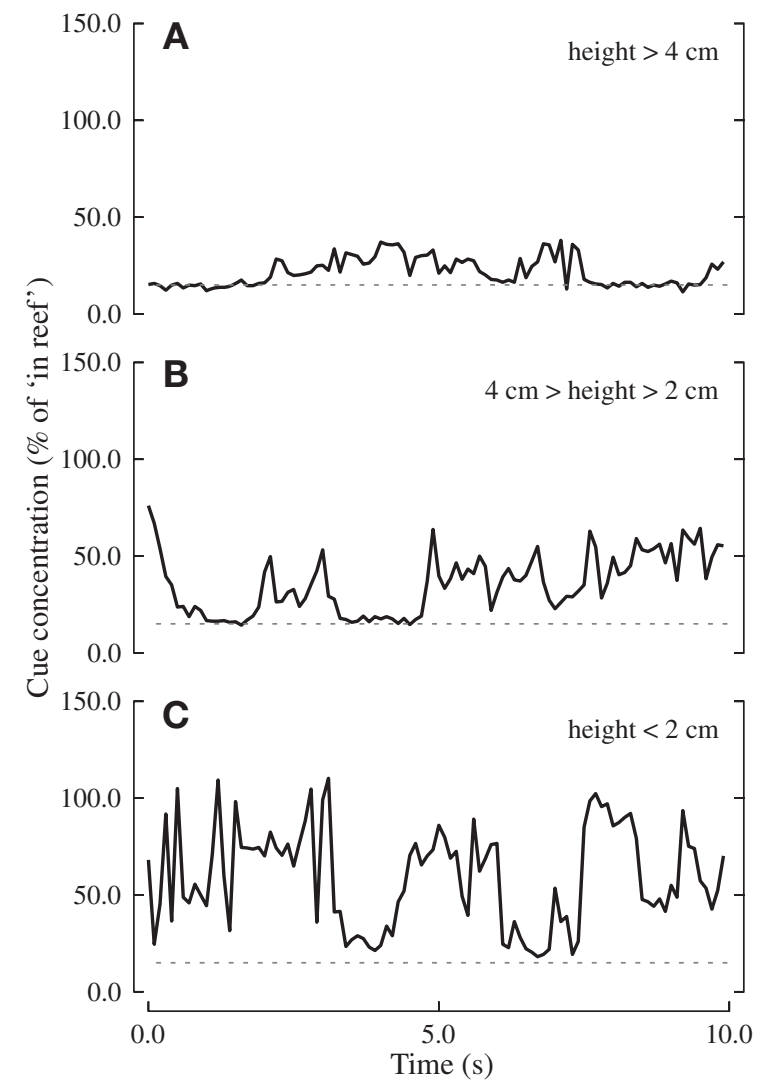

Fig. 4. Time history of the inducer concentration encountered by a typical larva as it swims and sinks through a filamentous inducer field. The inducer concentration is plotted at each time step for a model larva when it was (A) $>4 \mathrm{~cm}$ above the reef, (B) between 2 and $4 \mathrm{~cm}$ above the reef, and (C) $2 \mathrm{~cm}$ above the reef. Behavioral parameters as in Table 1 and flow conditions as measured in the flume. Dashed line: threshold inducer concentration required to cause larval sinking

\section{Vertical water flow}

Field measurements of water motion over porous Porites compressa reefs showed slow (generally $1 \mathrm{~cm}$ $\mathrm{s}^{-1}$ ) net flow over several wave cycles that was upward out of convex coral heads, downward into concave reef areas, and into the seaward edge of the reef (M. A. R. Koehl \& T. Cooper unpubl. data). Simulations in which the net vertical flow velocity was increased or decreased over the entire substratum show that the transport rate of larvae to the reef was increased dramatically with net downward water flow and decreased to near zero with upward flow (Fig. 5).

\section{Larval velocities}

Competent larvae of Phestilla sibogae swim in a random direction when not in inducer, and sink towards the substratum when in inducer above a threshold con- 


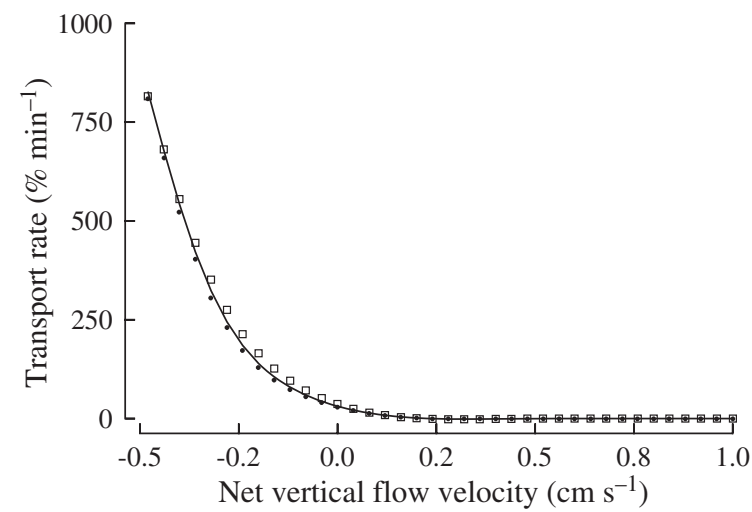

Fig. 5. Transport rate of Phestilla sibogae larvae into a Porites compressa reef, as a function of net vertical water velocity ( $x$-axis has been moved downwards to show the portions of the curve very close to zero). Positive velocities indicate water movement up out of the reef and negative velocities indicate movement down into the reef. Simulations run with an inducer threshold of 10 (ㅁ), 20 (line), and $30 \%(\bullet)$ of the 'in reef' concentration. Other behavioral parameters as in Table 1 and flow conditions as measured in the flume

centration (Hadfield \& Koehl 2004). We varied the speed at which larvae swam when not responding to inducer while holding all other behavioral and flow parameters at the measured values. Transport rate increased monotonically with increased swimming speed (Fig. 6A). Furthermore, for larvae that swam at low speeds when in inducer-free water, those that were stimulated to sink by low concentrations of inducer (i.e. that had low thresholds) settled slightly more rapidly than did those with higher thresholds. In contrast, there was not a monotonic effect of threshold on the rate of transport to the bottom for larvae that swam rapidly.

We performed similar simulations in which we varied the velocity at which larvae sank when responding to inducer. The transport rate of larvae to the reef increased monotonically with increases in sinking velocity (Fig. 6B). Lower threshold concentrations to induce sinking had little effect on the transport rates at very low sinking speeds, but tended to increase transport rates at high sinking speeds. The sensitivity of the larvae to inducer (i.e. inducer threshold) had a much greater influence on the effects of sinking speed on transport to the reef than it did on the effects of swimming speed on transport to the reef.

\section{Larval lag times}

Increasing the lag time between a larva's encounter with an inducer filament and the onset of sinking ('entrance lag') produced only a small reduction in the transport rate of larvae to the reef, while the time lag
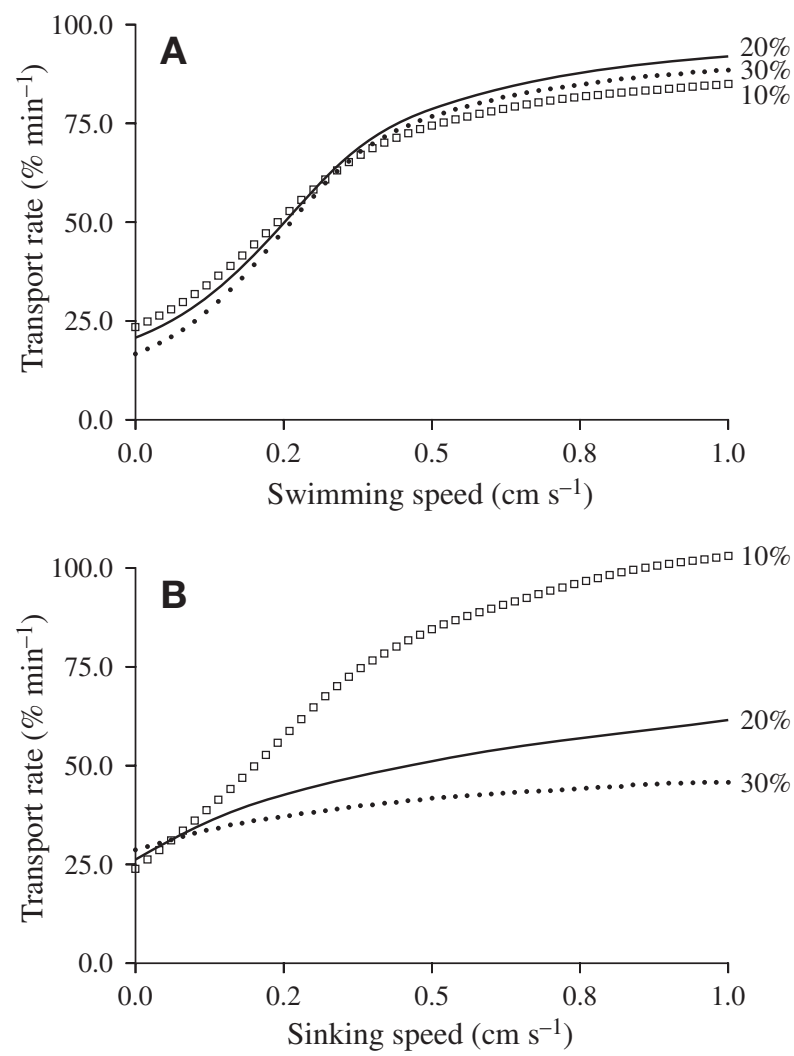

Fig. 6. Transport rate of Phestilla sibogae larvae into a Porites compressa reef, as a function of the speed of (A) larval swimming and (B) larval sinking. Simulations were run with an inducer threshold of $10 \%$ (口), $20 \%$ (line), and $30 \%(\bullet)$ of the 'in reef' concentration. Observed inducer threshold of $P$. sibogae as in Fig. 3; observed swimming and sinking speeds are 0.17 and $0.13 \mathrm{~cm} \mathrm{~s}^{-1}$, respectively (Hadfield \& Koehl 2004). Other behavioral parameters as in Table 1 and flow conditions as measured in the flume

between exit from the filament and resumption of swimming ('exit lag') had a negligible effect (Fig. 7).

\section{Larval responsivity}

Raising larval responsivity (the percentage of filaments to which a larva responds) caused a nearly linear increase in transport rate and magnified the effects of inducer threshold on transport rate (Fig. 8).

\section{Swimming direction}

All of the simulations mentioned above assumed that the distribution of swimming directions for a population of larvae was isotropic when the larvae were not in inducer, and that all the larvae sank downwards when responding to inducer. To explore the effects of swim- 

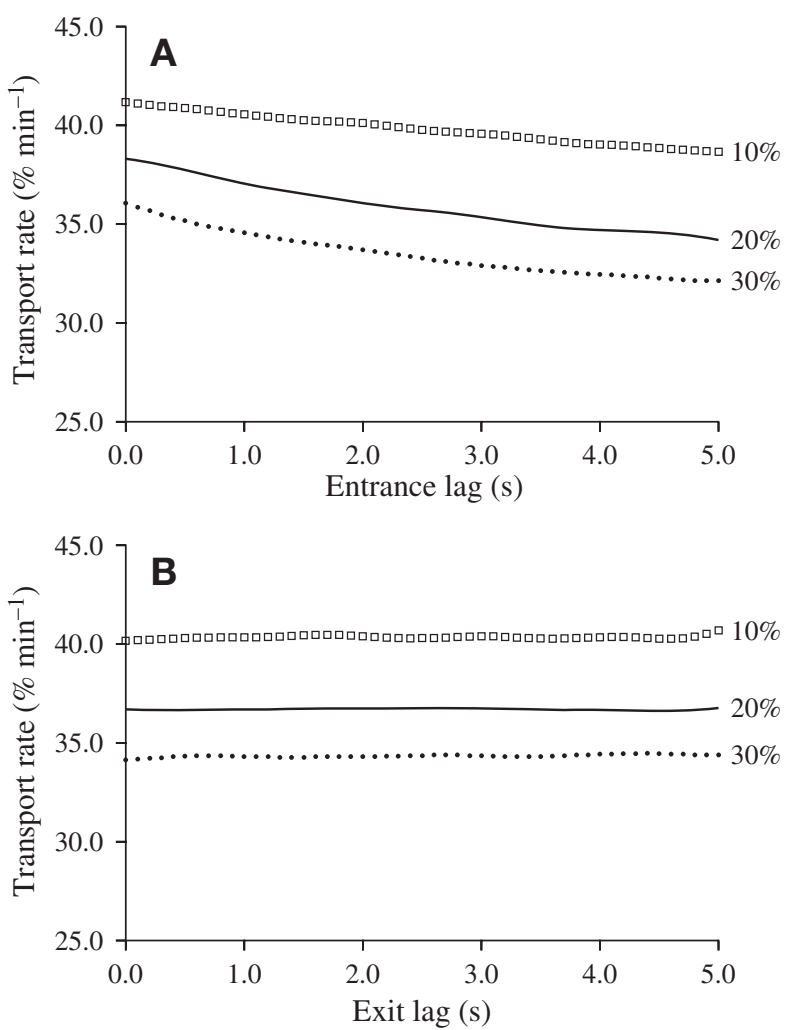

Fig. 7. Transport rate of Phestilla sibogae larvae into a Porites compressa reef, as a function of (A) entrance and (B) exit lag times. Entrance lag is the time interval between a larva's entry into an inducer filament and the start of larval sinking. Exit lag is the time required for a larva to resume swimming after it exits an inducer filament. Simulations run with an inducer threshold of 10 (), 20 (line), and $30 \%(\bullet)$ of the 'in reef' concentration. Observed inducer threshold of $P$. sibogae as in Fig. 3; observed entrance and exit lags are 1.60 and $0.00 \mathrm{~s}$, respectively. Other behavioral parameters as in Table 1 and flow conditions as measured in the flume

ming direction, we also ran simulations in which all the larvae in a population swam in the same direction at $0.17 \mathrm{~cm} \mathrm{~s}^{-1}$ when in inducer-free water and sank at $0.13 \mathrm{~cm} \mathrm{~s}^{-1}$ when in inducer (Fig. 9A). These simulations showed that the transport rate of larvae to the reef is dramatically increased when larvae in inducerfree water swim downwards toward the reef. In contrast, the transport rate of larvae to the reef decreased when larvae in inducer-free water swim upwards, away from the reef. Furthermore, the transport rate was unaffected by whether larvae swimming horizontally moved with or against the ambient flow.

We also ran simulations to explore the consequences of swimming in a particular direction, rather than sinking, when responding to inducer. For these simulations the larvae swam at $0.17 \mathrm{~cm} \mathrm{~s}^{-1}$ in directions that were randomly chosen (i.e. the distribution of directions for the population was isotropic), but all the larvae responding to inducer swam at the 'response speed' of

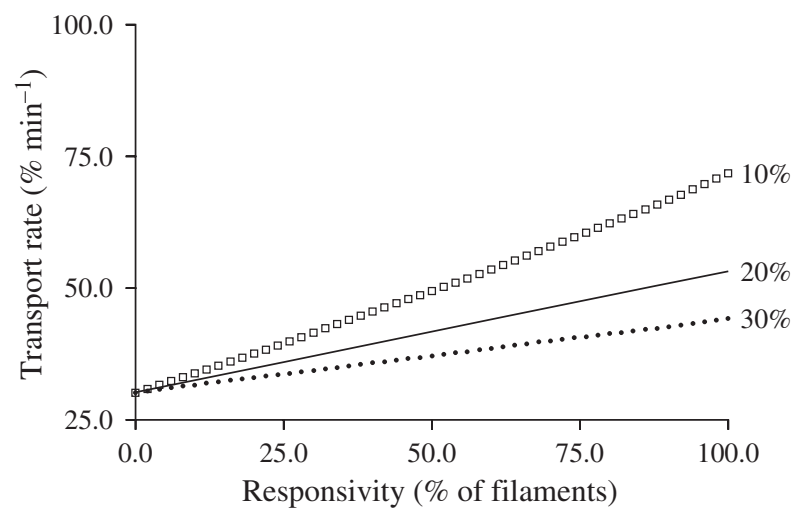

Fig. 8. Transport rate of Phestilla sibogae larvae into a Porites compressa reef, as a function of larval responsivity (percentage of inducer filaments to which a larva responds). Simulations run with an inducer threshold of $10 \%$ (), $20 \%$ (line), and $30 \%(\bullet)$ of the 'in reef' concentration. Observed inducer threshold of $P$. sibogae as in Fig. 3; observed responsivity is approximately $27 \%$. Other behavioral parameters as in

Table 1 and flow conditions as measured in the flume

$0.13 \mathrm{~cm} \mathrm{~s}^{-1}$ in a single direction (Fig. 9B). As expected, the rates of transport of larvae into the reef were greater for larvae swimming downwards, were lower for larvae swimming upwards, and were unaffected by ambient flow direction for larvae swimming horizontally. However, the magnitudes of these effects of the direction of swimming when responding to inducer (Fig. 9B) were not as great as they were for swimming direction when in inducer-free water (Fig. 9A) for 2 reasons: 'response speed' of swimming in inducer is slower than swimming speed in inducer-free water, and larvae only responded to $27 \%$ of the inducer filaments encountered.

As explained in 'Materials and methods', we used an arbitrary choice for the reorientation variance (the variance of the angle between the swimming velocity of a larva before it enters an inducer filament and its velocity after exiting that filament). To determine the effect of this assumption on our results, we ran the model at a range of reorientation variances (Fig. 9C). While the transport rate did decrease with increases in reorientation variance, this effect was very small at low variances and negligible at high variances.

\section{Depletion of larvae}

We assumed that larvae transported into the reef stayed there (justification provided in 'Materials and methods'); hence, the number of larvae remaining in the water was reduced as it flowed across the reef. We estimated the spatial distribution across the reef of larval transport into the reef by assuming larvae were transported into the reef at a uniform rate: 
A

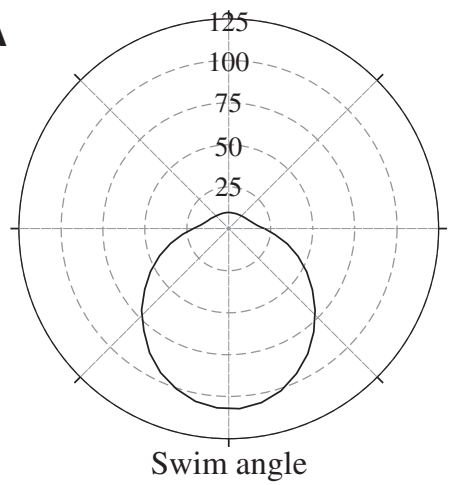

B
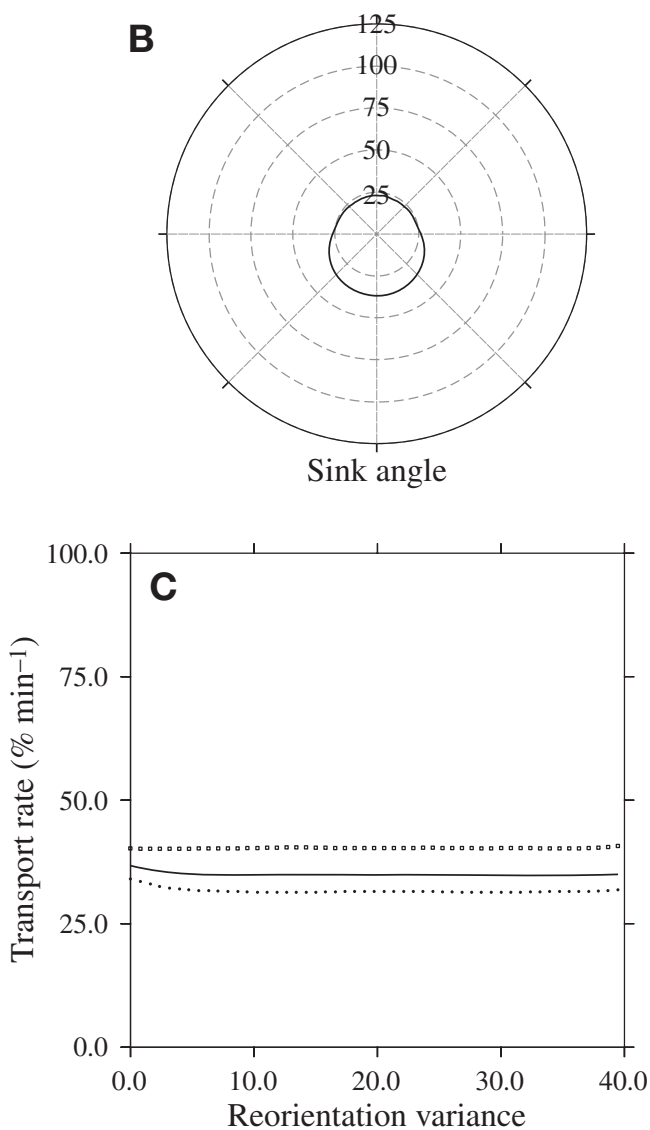

Fig. 9. (A) Transport rate for a population of larvae that all swim in the same direction (swim angle) at $0.17 \mathrm{~cm} \mathrm{~s}^{-1}$ when out of inducer and sink at $0.13 \mathrm{~cm} \mathrm{~s}^{-1}$ when in inducer. (B) Transport rate for a population of larvae that all move in the same direction (sink angle) at $0.13 \mathrm{~cm} \mathrm{~s}^{-1}$ when in inducer, but swim in random directions when out of inducer. In (A) and (B), direction is given by angle and transport rate $\left(\% \mathrm{~min}^{-1}\right)$ is indicated by the radial distance. Threshold concentration assumed for (A) and (B) is $15 \%$ of the 'in reef' concentration. (C) Transport rate as a function of the reorientation variance. After a larva exits from an inducer filament, its swimming direction (angle in the $x, z$ plane) was perturbed by an angle randomly selected from a normal distribution with a mean of zero and a variance we call the 'reorientation variance' Simulations were run with an inducer threshold of $10 \%$ (), $20 \%$ (line), and 30\% $(\bullet)$ of the 'in reef' concentration. Other behavioral parameters as in Table 1 and flow conditions as measured in the flume

$$
\frac{\mathrm{d} N}{\mathrm{~d} t}=-T N
$$

where $N$ is the percentage of larvae still in the water column and $T$ is the transport rate to the substratum. Hence, the horizontal distribution across the reef of larval settlement into the reef was:

$$
\rho=\frac{T}{u_{\infty}} \exp \left(-\frac{T x}{u_{\infty}}\right)
$$

where $u_{\infty}$ is the time-averaged freestream flow speed and $x$ is the horizontal distance from the upstream edge of the inducer-releasing reef. The settlement distribution function is then:

$$
F=1-\exp \left(-\frac{T x}{u_{\infty}}\right)
$$

Taking a specific case of the above equation, we expect $90 \%$ of the larvae to settle in a distance equal to:

$$
x=\frac{u_{\infty}}{T} \log (10)
$$

Using the rate of larval transport into the reef calculated for measured parameters of larval behavior, flow, and inducer fields in the flume, we predicted that $90 \%$ of the larvae should settle in the first $7.3 \mathrm{~m}$ of the coral reef. However, this is a rough estimate because we neglected changes in the inducer field and turbulence that probably occur at the upstream edge of the reef as well as possible replenishment of larvae via mixing from higher regions of the water column. The latter was a reasonable approximation for reefs we studied in Kaneohe Bay, where height of the water column above reefs was often $<0.5 \mathrm{~m}$. Our rough estimate suggests that most settlement of Phestilla sibogae larvae should occur in the upstream (seaward) region of a reef.

\section{DISCUSSION}

Our individual-based model of larvae in the water column in turbulent, wave-driven water flow shows that the larval behavior of sinking in response to dissolved settlement cue can increase the rate of larval transport to the substratum. We found that, on the scale of centimeters to millimeters, physical processes and larval behavior both affect the transport of larvae to the bottom.

\section{Fine-scale distribution of chemical cues in the water}

The instantaneous spatial distribution of a dissolved chemical cue released from the substratum and mixed into turbulent flowing water is filamentous if measured on the spatial scale of microscopic organisms like larvae. Therefore, as larvae move through the water, 
they encounter pulses of high cue concentration interspersed with patches of low or no cue. Earlier analyses of effects of dissolved inducers from the benthos on larval transport to the bottom assumed a constant, smooth concentration gradient (see 'Introduction'). While such models are not appropriate for exploring the consequences of processes on the fine spatial and temporal scales relevant to individual larvae, we found that using the simplifying assumption of a smooth concentration gradient to calculate larval transport rates produces overestimates of $15 \%$ or less (depending on inducer threshold concentration to trigger larval sinking). Our results counter the suggestion of Crisp \& Meadows (1962) that larvae are too small to detect and use for navigation a concentration gradient of dissolved settlement cue. We found that there is a gradient in the number of filaments of inducer encountered per unit time by larvae as a function of their height above the substratum, and that their rapid response of sinking when in those filaments enhances their transport to the bottom. Furthermore, we found that, even if we assume a continuous concentration of inducer, a sinking response to local inducer concentration above threshold can enhance larval transport to the substratum without requiring that each larva sense a concentration gradient across the width of its body.

\section{Larval transport in turbulent, wave-driven flow}

Many studies of larval settlement assumed that larvae are transported like passive particles in the benthic boundary layer (e.g. Hannan 1984, Butman 1987). We found that assuming that larvae sink continuously like passive particles leads to over-estimation of transport rates for larvae such as those of Phestilla sibogae that sink only while in inducer above threshold concentration. Eckman et al. (1994) calculated that a steep increase in the downward velocity of larvae as they near the bottom (as might occur in response to chemical cues in water along the substratum) enhances settlement rate, and Finelli \& Wethey (2003) observed such behavior in oyster larvae. Similarly, our model showed that sinking responses to dissolved settlement inducer, even by small, weakly swimming, slow-sinking microscopic larvae, can increase their transport rate to the substratum in turbulent, wave-driven flow.

High turbulence should increase the rate of larval transport to the substratum for several reasons. Like earlier models (e.g. Eckman 1990, Gross et al. 1992), our calculations showed that simply increasing the vertical stirring of the larvae-carrying water by raising the turbulence could enhance the rate of transport of larvae to the substratum. We have not included those calculations in this paper, however, because we did not have PLIF videos of the dispersion of the inducer field at high turbulence, which would have affected when larvae sank or swam. Sinking in high shear, as Fuchs et al. (2004) observed for snail veliger larvae, should further increase transport rates to the substratum in high turbulence. In addition, a synergistic interaction between larval responses to simultaneous exposure to inducer and to shear might affect their movement towards the substratum. Since both the frequency of encounters with inducer filaments and the local shear increase as larvae near the substratum, the quantitative effect on larval transport rates of a sinking response to shear should depend on the threshold values of shear and of inducer required to stimulate sinking. We did not include a sinking response by larvae to high local shear in the present analysis because the behavior of $P$. sibogae in high shear is not yet known.

In the orbital motion of wave-driven flow characteristic of shallow coastal sites, both larvae and dissolved cues from the benthos are carried back-and-forth rapidly, but are transported slowly across the habitat (e.g. Koehl \& Powell 1994). In waves, larvae have more time over a patch of inducer-releasing substratum than they would in a unidirectional current moving at the same peak velocity. Our model predicts that most of the larvae in the water slowly advecting across a shallow reef in wave-driven flow should be transported into the upstream portion of the reef. Field observations on patch reefs in Kaneohe Bay, Hawaii, are consistent with this prediction: more larval mimics (particles with sinking velocities like competent Phestilla sibogae larvae responding to inducer) released upstream (seaward) of reefs landed on seaward regions of the reefs than on downstream backreef areas, and recruitment of $P$. sibogae was heavier on upstream than on downstream parts of reefs (Hadfield et al. 2007).

While earlier models of larval settlement have dealt with solid substrata (Eckman 1990, Gross et al. 1992, Eckman et al. 1994, McNair et al. 1997, McNair 2000), we considered a porous substratum (branching coral) through which water flows. Studies of flow through branching corals in the field (e.g. Koehl \& Hadfield 2004, M. A. R. Koehl \& T. Cooper unpubl. data) and in laboratory flumes (e.g. Chamberlain \& Graus 1975, Reidenbach 2004) have shown that water flows vertically into and out of the spaces within a reef, with slow (generally $\leq 1 \mathrm{~cm} \mathrm{~s}^{-1}$ ) net flow upwards over convex coral heads and downwards in depressions. Since our model showed that net vertical flow up out of a reef reduces or stops larval transport to the reef, whereas net vertical flow downwards increases the transport, we predict that settlement of larvae on coral reefs should be spatially patchy on the scale of $\leq 1 \mathrm{~m}$, depending on the local reef topography. 


\section{Aspects of behavior affecting transport}

Several aspects of larval behavior have large effects on larval transport to the substratum. For example, the sensitivity of larvae to inducer (threshold concentration to stimulate sinking) has a substantial, non-linear effect on transport rate. The inducer threshold of larvae of Phestilla sibogae (Hadfield \& Paul 2001) is in the range where changes in sensitivity have a large effect on settlement rate. The responsivity of larvae to inducer (percentage of inducer filaments encountered that elicit sinking) also has a large, but linear, effect on transport rate to the substratum. Increases in larval sinking velocity raise transport rates to the bottom, as do increases in swimming speed for the case where those larvae in inducer-free water swim isotropically in all directions.

In contrast, the lag times for larvae to initiate sinking after encountering a filament of inducer, or to resume swimming after exiting a filament into inducer-free water, have minor effects on the rate of transport of larvae to the substratum. We explored a range of lag times up to 3 times greater than those measured for Phestilla sibogae larvae, but did not consider lag times so long that larvae would have entered the next filament before reacting to the previous one. This result suggests that although larvae with short lag times sink in response to filaments more frequently, these additional responses are also of short duration and thus have relatively little effect on the transport rate. That lag time has only a small effect on transport rate supports our simplifying assumptions that larvae reach terminal velocity as soon as they start sinking, and that larvae attain their swimming speed as soon as they commence beating their velar cilia. Therefore, these assumptions should have little effect on our conclusions.

The behavior of competent larvae of Phestilla sibogae differs from that of precompetent larvae. For example, precompetent larvae swim towards the light (upwards), whereas competent larvae do not show this positive phototaxis (Miller \& Hadfield 1986). Our model predicts that upwards swimming substantially reduces larval transport to the substratum, thereby enhancing the ability of precompetent larvae to be carried away from the reef where they hatched. Furthermore, although precompetent larvae retract their swimming organs briefly upon encountering inducer filaments, they quickly resume swimming while still in inducer (Hadfield \& Koehl 2004). Since the proportion of a larva's time spent sinking downwards has a large effect on its transport to the substratum, precompetent larvae should be less likely to be carried into the reef than competent larvae. Thus, the ontogenetic changes in behavior of the larvae of $P$. sibogae should improve chances for escape of precompetent larvae from their parent reefs, thereby enhancing their transport to new sites, and should lead to the settlement of competent larvae in suitable habitats on reefs releasing cue from Porites compressa.

\section{Limitations of our model}

In our model, we used matched spatially and temporally varying turbulence and inducer fields that were measured under the same flow conditions in a flume, but that were not recorded simultaneously. Although we matched the advection of larvae to the advection of the inducer field for both the current and the waves, our approximation of turbulence might have increased the variance in inducer encountered by a larva (as explained in 'Materials and methods'). We used several approaches to assess the consequences of this approximation of turbulence. Roughly as many larvae should be moved out of inducer filaments as are moved into inducer filaments due to our model artifact. Therefore, if larvae respond rapidly to inducer, the net effect of our approximation on the rate of transport to the substratum of a population of larvae in the water column should be small. Our finding that entrance and exit lag times had little effect on the transport rate of larvae to the reef suggests that our model should be robust to small increases in inducer variation. We also examined an extreme case of decoupling the inducer and velocity field to suggest an upper bound on the magnitude of the error introduced by not having simultaneous PLIF and ADV measurements. When the model was run with a constant, smooth inducer field rather than with a time-varying filamentous inducer field, we found an increase of $\leq 15 \%$ on the transport rate (Fig. 3C). Although we expect that the error resulting from not having simultaneous measurements of the velocity and scalar fields is small, an interesting area for future research would be individual-based modeling of the trajectories of microscopic organisms such as larvae in simultaneously measured instantaneous fine-scale velocity fields that carry them and chemical fields that affect their behavior.

Our model was 2-dimensional; thus, we assumed that larvae only move in the plane we analyzed (i.e. in the streamwise and vertical directions). However, larvae can swim in any direction, and both larvae and inducer can be moved into and out of the plane we are analyzing by turbulence, which is 3-dimensional. Therefore, a real larva moving in 3 dimensions might have a different probability of encountering an inducer filament than our 2-dimensional model predicts. Our ADV measurements of flow over the reef in the flume showed that the turbulence mixing term in the vertical plane that we modeled $\left(u^{\prime} w^{\prime}\right)$ was about 4 times 
greater than in the horizontal plane $\left(u^{\prime} v^{\prime}\right)$ (Reidenbach 2004). Although vertical mixing was dominant in the flow conditions we modeled, our estimates of larval transport rates to the bottom could be affected if real larvae moving in 3 dimensions have a different probability of encountering inducer (and therefore of sinking) or exiting an inducer filament (and therefore of ceasing to sink) than our 2-dimensional model predicts.

Our model is the first step towards coupling behavioral algorithms in an individual-based model with instantaneous flow and scalar-concentration data recorded on the fine spatial and temporal scales relevant to individual microscopic organisms. We used measurements of time-varying, fine-scale distributions of dissolved substances released by a model reef in a flume in which one set of wave conditions measured in the field were mimicked (Reidenbach 2004). When data become available, future studies should explore the consequences to larval transport of different flow conditions. For example, we considered wave-driven flow like that measured in the field, whereas in unidirectional currents larvae and inducers would have shorter residence times over a patch of habitat, and the filaments of inducer in the water would tend to be narrower, lower in concentration, and closer to the bottom than they are in waves (reviewed in Koehl 2006). Similarly, we did not vary the fine-scale spatial distribution of cue for a range of intermediate values of turbulence in our model because such PLIF data for Porites compressa reefs are not available. Greater turbulence should mix chemicals released from the substratum higher into the water column and create finer filament structure (e.g. Koehl 2006). Future models might explore larval transport for a range of turbulence intensities and for different frequency spectra of velocity fluctuations (e.g. larger scales of turbulence occur in nature than can be produced in a flume). Our model assumed a uniform net vertical flow over the entire reef, whereas real reefs have a patchy distribution (on spatial scales of $\sim 1 \mathrm{~m}$ ) of net upward and downward flow (M. A. R. Koehl \& T. Cooper unpubl. data). Furthermore, we studied only a rigid, rough, porous substratum (coral reef), but it would be interesting to investigate the effects of different types of substrata (e.g. porous versus solid substrata of different roughness, flexible macrophyte versus rigid coral canopies of different densities). In addition, future research should focus on the consequences of inducer distribution and larval transport of larger patches of inducer-releasing substratum upstream from the portion of the bottom being modeled.

Acknowledgements. This research was supported by NSF grants OCE-9907120 (M.A.R.K.) and OCE-9907545 (M.G.H.), the Virginia G. and Robert E. Gill Chair (M.A.R.K.), Gompertz Fellowship (J.A.S.), Howard Hughes Medical Foundation Bio- logy Fellows Program (J.A.S.), and Undergraduate Research Apprentice Program at University of California, Berkeley, and a Stanford Graduate Fellowship, Stanford University (M.A.R.).

\section{LITERATURE CITED}

Abelson A, Denny M (1997) Settlement of marine organisms in flow. Annu Rev Ecol Sys 28:317-339

Boudreau B, Bourget E, Simard Y (1993) Behavioural responses of competent lobster postlarvae to odor plumes. Mar Biol 117:63-69

Butman CA (1987) Larval settlement of soft-sediment invertebrates - the spatial scale of pattern explained by active habitat selection and the emerging role of hydrodynamical processes. Oceanogr Mar Biol 25:113-165

Chamberlain IA, Graus RR (1975) Water flow and hydromechanical adapations of branched reef corals. Bull Mar Sci 25:112-125

Crimaldi JP, Koseff JR (2001) High-resolution measurments of the spatial and temporal scalar structure of a turbulent plume. Exp Fluids 31:90-102

Crisp DJ (1974) Factors influencing the settlement of marine invertebrate larvae. In: Grant PT, Mackie AM (eds) Chemoreception in marine organisms. Academic Press, London, p 177-265

Crisp DJ, Meadows PS (1962) The chemical basis of gregariousness in cirripedes. Proc R Soc London B 156:500-520

Dean RG, Dalrymple RA (1991) Water wave mechanics for engineers and scientists. World Scientific Publishing Company, Singapore

Denny M (1988) Biology and the mechanics of the waveswept environment. Princeton University Press, Princeton, NJ

Denny MW, Shibata MF (1989) Consequences of surf-zone turbulence for settlement and external fertilization. Am Nat 134:859-889

Eckman JE (1990) A model of passive settlement by planktonic larvae onto bottoms of differing roughness. Limnol Oceanogr 35:887-901

Eckman JE (1996) Closing the larval loop: linking larval ecology to the population dynamics of marine benthic invertebrates. J Exp Mar Biol Ecol 200:207-237

Eckman JE, Werner FE, Gross TF (1994) Modeling some effects of behavior on larval settlement in a turbulent boundary layer. Deep-Sea Res II 41:185-208

Finelli CM, Wethey DS (2003) Behavior of oyster larvae (Crassostrea virginica) larvae in flume boundary layer flows. Mar Biol 143:703-711

Fuchs HI, Mullineaux LS, Solow AR (2004) Sinking behavior of gastropod larvae (Ilyanassa obsoleta) in turbulence. Limnol Oceanogr 49:1937-1948

Gousbet G, Berlemont A (1999) Eulerian and Lagrangian approaches for predicting the behaviour of discrete particles in turbulent flows. Prog Energy Combust Sci 25:133-159

Grant W, Madsen O (1979) Combined wave and current interaction with a rough bottom. J Geophys Res 84:1797-1808

Grassle JP, Butman CA (1989) Active habitat selection by larvae of the polychaetes, Capitella spp. I and II, in a laboratory flume. In: Ryland JS, Tyler PA (eds) Reproduction, genetics and distributions of marine organisms. Olsen \& Olsen, Fredensborg, p 107-114

Gross TF, Werner FE, Eckman JE (1992) Numerical modeling of larval settlement in turbulent bottom boundary layers. J Mar Res 50:611-642

Hadfield M (1977) Chemical interactions in larval settling of a marine gastropod. In: Faulkner DJ, Fenical WH (eds) 
Marine natural products chemistry. Plenum, New York, p 403-413

Hadfield MG, Koehl MAR (2004) Rapid behavioral responses of an invertebrate larva to dissolved settlement cue. Biol Bull 207:28-43

Hadfield MG, Paul VJ (2001) Natural chemical cues for settlement and metamorphosis of marine-invertebrate larvae. In: McClintock JB, Baker BJ (eds) Marine chemical ecology. CRC Press, Boca Raton, FL, p 431-461

Hadfield MG, Pennington JT (1990) Nature of the metamorphic signal and its internal transduction in larvae of the nudibranch Phestilla sibogae. Bull Mar Sci 46:455-464

Hadfield M, Scheuer D (1985) Evidence for a soluble metamorphic inducer in Phestilla: ecological, chemical and biological data. Bull Mar Sci 37:556-566

Hadfield M, Meleshkevitch EA, Boudko D (2000) The apical sensory organ of a gastropod veliger is a receptor for settlement cues. Biol Bull 198:67-76

Hadfield MG, Faucci A, Koehl MAR (2007) Measuring recruitment of larvae in a complex field environment: the corallivorous nudibranch Phestilla sibogae (Bergh). J Exp Mar Biol Ecol 338:57-72

Hannan CA (1984) Planktonic larvae may act as passive particles in tubulent near-bottom flows. Limnol Oceanogr 29:1108-1116

Harvey ME, Bourget E, Ingram RG (1995) Experimental evidence of passive accumulation of marine bivalve larvae of filamentous epibenthic structure. Limnol Oceanogr 40: 94-104

Havenhand JN, Svane I (1991) Roles of hydrodynamics and larval behavior in determining spatial aggregation in the tunicate Ciona intestinalis. Mar Ecol Prog Ser 68:271-276

Hunter JR, Craig PD, Phillips HE (1993) On the use of random walk models with spatially variable diffusivity. J Comput Phys 106:36-376

Keough MJ, Downes BJ (1982) Recruitment of marineinvertebrates - the role of active larval choices and early mortality. Oecologia 54:348-352

Koehl MAR (1977) Effects of sea anemones on the flow forces they encounter. J Exp Biol 69:87-105

Koehl MAR (2006) The fluid mechanics of arthropod sniffing in turbulent odor plumes. Chem Senses 31:93-105

Koehl MAR, Hadfield MG (2004) Soluble settlement cue in slowly-moving water within coral reefs induces larval adhesion to surfaces. J Mar Systems 49:75-88

Koehl MAR, Powell TM (1994) Turbulent transport of larvae near wave-swept rock shores: Does water motion overwhelm larval sinking? In: Wilson $\mathrm{H}$, Shinn G, Stricker S (eds) Reproduction and development of marine invertebrates. Johns Hopkins University Press, Baltimore, MD, p 261-274

Koehl MAR, Koseff JR, Crimaldi JP (2001) Lobster sniffing: antennule design and hydrodynamic filtering of information in an odor plume. Science 294:1948-1951

McNair JN (2000) Turbulent transport of suspended particles and dispersing benthic organisms: the hitting-time distribution for the local exchange model. J Theor Biol 202: 231-246
McNair JN, Newbold JD, Hart DD (1997) Turbulent transport of suspended particles and dispersing benthic organisms: how long to hit bottom? J Theor Biol 188:29-52

Mead KS, Wiley MB, Koehl MAR, Koseff JR (2003) Fine-scale patterns of odor encounter by the antennules of mantis shrimp tracking turbulent plumes in wave-affected and unidirectional flow. J Exp Biol 206:181-193

Miller SE, Hadfield MG (1986) Ontogeny of phototaxis and metamorphic competence in larvae of the nudibranch Phestilla sibogae Bergh (Gastropoda: Opisthobranchia). J Exp Mar Biol Ecol 97:95-112

Mullineaux LS, Butman CA (1991) Initial contact, exploration, and attachment of barnacle (Balanus amphitrite) cyprids settling in flow. Mar Biol 110:93-103

Pawlik JR (1993) Settlement of a marine tube worm as a function current velocity: interacting effects of hydrodynamics and behavior. Limnol Oceanogr 38:1730-1740

Reidenbach MA (2004) Boundary layer dynamics in coral reef systems. PhD thesis, Stanford University, Stanford, CA

Reidenbach MA, Koseff JR, Monismith SG, Steinbuck JV, Genin A (2006) The effects of waves and morphology on mass transfer within branched reef corals. Limnol Oceanogr 51:1134-1141

Roughgarden JS, Gaines SD, Pacala SW (1987) Supply side ecology: the role of physical transport processes. In: Gee JHR, Giller PS (eds) Organization of communities: past and present. Blackwell Scientific Publications, Palo Alto, CA, p 491-518

Su LD, Dahm WJA (1996a) Scalar imaging velocimetry measurements of the velocity gradient tensor field in turbulent flows. 1. Assessment of errors. Phys Fluids 8:1869-1882

Su LD, Dahm WJA (1996b) Scalar imaging velocimetry measurements of the velocity gradient tensor field in turbulent flows. 2. Experimental results. Phys Fluids 8:1883-1906

Tamburri MN, Finelli CM, Wethey DS, Zimmer-Faust RK (1996) Chemical induction of larval settlement behavior in flow. Biol Bull 191:367-373

Turner EJ, Zimmer-Faust RK, Palmer MA, Luckenbach M, Pentcheff ND (1994) Settlement of oyster (Crassostrea virginica) larvae: effects of water flow and a water-soluble chemical cue. Limnol Oceanogr 37:1579-1593

Visser A (1997) Using random walk models to simulate the vertical distribution of particles in a turbulent water column. Mar Ecol Prog Ser 158:275-281

Walters LJ, Hadfield MG, delCarmen KA (1997) The importance of larval choice and hydrodynamics in creating aggregations of Hydroides elegans (Polychaeta: Serpulidae). Invert Biol 116:102-114

Welch JM, Rittschof D, Bellock TM, Forward RB Jr (1997) Effects of chemical cues on settlement behavior of blue crab Callinectes sapidus postlarvae. Mar Ecol Prog Ser 154:143-153

Yamazaki H, Mackas DL, Denman K (2002) Coupling small scale physical processes with biology. In: Robinson $A R$, McCarthy JJ, Rothschild BJ (eds) Biological-physical interactions in the sea. John Wiley \& Sons, New York, p 51-112 
Appendix 1. Turbulence model correction term from Hunter et al. (1993) is negligible in our study

Modeling turbulence as a simple stochastic process when there is a spatial gradient in turbulence can produce an artifact in calculations of particle transport wherein non-physical migration of particles into areas of low variance occurs (e.g. Hunter et al. 1993, Visser 1997, Yamazaki et al. 2002). Here we show that the correction term for this artefact suggested by Hunter et al. (1993) is negligible for our model. We use the following Lagrangian equation of motion that calls the 'naive' model, which we express in terms of standard deviation (rather than diffusion coefficient used by Hunter et al. 1993) to be consistent with the rest of this paper:

$$
z_{n+1}=z_{n}+u_{z} \delta t+p \sigma_{z} \delta t
$$

where $z_{n}$ is the height above the coral at the $n$th iteration, $u_{z}$ is the vertical advection velocity, $\delta t$ is the duration of a time step, $p$ is a random number with mean zero and a standard deviation of 1. Hunter et al. (1993) suggest the following correction to compensate for bias introduced by a gradient in turbulent diffusion:

$$
z_{n+1}=z_{n}+v \delta t+p \sigma_{z} \delta t+\frac{1}{2}\left(\delta t^{2} \partial_{z} \sigma_{z}^{2}\right)
$$

We assumed that the variance is proportional to height above the coral. From Eq. (11), we find that this correction is equal to a constant downwards velocity of about $0.001 \mathrm{~cm}$ $\mathrm{s}^{-1}$, which is less than $1 \%$ of the larval sinking velocity.

Submitted: October 11, 2006; Accepted: March 2, 2007 Proofs received from author(s): April 5, 2007
Editorial responsibility: Steven Morgan (Contributing Editor), Bodega Bay, California, USA 